Revista Destaques Acadêmicos, Lajeado, v. 12, n. 3, 2020. ISSN 2176-3070

DOI: http://dx.doi.org/10.22410/issn.2176-3070.v12i3a2020.2658

http://www.univates.br/revistas

\title{
FATORES QUE INFLUENCIAM A INTERRUPÇÃO PRECOCE DO ALEITAMENTO MATERNO EXCLUSIVO: UMA REVISÃO INTEGRATIVA
}

\author{
Jessica Maria Moccelin ${ }^{1}$, Raquel Vieira Schuster ${ }^{2}$
}

\begin{abstract}
Resumo: Esse estudo possui o objetivo de analisar na literatura científica disponível os fatores que influenciam na interrupção precoce do aleitamento materno exclusivo. Tratase de uma revisão integrativa da literatura realizada no portal da Scientific Eletronic Library Online (SciELO). Para o estudo foram analisados e discutidos nove artigos científicos selecionados, sendo utilizadas aproximações com a Análise de Conteúdo. Os resultados indicaram cinco principais fatores que influenciam no desmame precoce sendo eles: o trabalho materno, os mitos e as crenças sobre o leite materno, o uso de mamadeira e chupetas, introdução de outros tipos de leite e os problemas mamários. Evidenciou-se também a necessidade de implementar estratégias de promoção do aleitamento materno e capacitar os profissionais a fim de possibilitar a ampliação e adequado conhecimento para a população.
\end{abstract}

Palavras-chave: Aleitamento Materno; Desmame Precoce; Fatores de Risco.

\section{Introdução}

O Aleitamento Materno (AM) é uma prática milenar, tornando-se uma importante estratégia para reduzir a mortalidade infantil (BRASIL, 2015). O Ministério da Saúde (MS) em consonância com a Organização Mundial da Saúde (OMS) recomendam que o AM deve ser a forma exclusiva de amamentação até o sexto mês de vida do recém-nascido, e a partir dessa idade, é indicado um complemento ao leite materno, sendo oferecidos outros líquidos e/ou alimentos adequados a cada criança. O AM, sob livre demanda, deve ser ofertado até dois anos de idade ou mais, devendo ser iniciado ainda na sala de parto, na primeira hora de vida (MACIEL et al., 2016).

1 Enfermeira. Universidade do Vale do Taquari - Univates. Lajeado - RS - Brasil.

2 Enfermeira. Mestre em Enfermagem. Universidade do Vale do Rio dos Sinos - UNISINOS. Porto Alegre - RS - Brasil. 
O Aleitamento Materno Exclusivo (AME) é definido pela OMS e reconhecido no mundo inteiro (WHO, 2019) como a oferta única de leite materno ao lactente, direto da mama ou ordenhado, ou leite humano de outra fonte, sem outros líquidos ou sólidos, com exceção de gotas ou xaropes contendo vitaminas, sais de reidratação oral, suplementos minerais ou medicamentos.

As vantagens do AME até os seis meses de idade são consideradas mais efetivas do que o AM até três ou quatro meses de idade seguido de aleitamento misto, o qual introduz outras fontes alimentares para a criança (PRADO et a. 2016). Conforme Santos et al. (2016) as vantagens do AME estão relacionadas a prevenção de alergias e problemas respiratórios, diminuição do risco de infecção gastrintestinal e desenvolvimento psicológico mais favorável.

Além de todas as vantagens mencionadas para os indivíduos amamentados, Rocci e Fernandes (2014) descrevem que a prática do AM também oferece importantes benefícios para a saúde da mulher que amamenta como: auxílio na involução uterina, tardamento a volta da fertilidade, reduz a probabilidade de ocorrência de câncer mamário e ovariano, além de fortalecer a relação de vínculo do binômio mãe/filho.

Apesar dos inúmeros benefícios já reconhecidos e amplamente divulgados do $\mathrm{AM}$, sua prática está aquém das recomendações em todo o mundo. Conforme dados do Fundo das Nações Unidas para a Infância (2019) apenas quatro em cada dez lactentes no mundo são alimentados exclusivamente com o leite materno nos primeiros seis meses de vida.

As altas taxas de mortalidade infantil no Brasil fizeram surgir um movimento em prol do retorno da prática de amamentação. A partir de então, muitas ações de incentivo ao AM foram elaboradas e respaldadas por políticas públicas como uma das principais estratégias de combate à morbimortalidade infantil (BRASIL, 2017). No entanto, apesar das políticas e investimentos para melhorar os níveis de AME no País, o desmame precoce representa um problema frequente.

De acordo com os dados do IBGE (2019), a taxa de mortalidade infantil no Brasil - medida pelo número de mortes antes de completar um ano de idade - foi de 14,9 a cada mil nascidos vivos, no ano de 2017. Já em 2018, esta taxa foi de 14,4 por mil, declínio de 3,4\% em relação ao ano anterior. Em alusão, Nunes (2015) estima que o AM poderia prevenir 13\% de todas as mortes por doenças evitáveis em crianças com idade inferior a 5 anos em todo o mundo.

O desmame precoce é definido como sendo a interrupção do AM antes de o bebê completar seis meses de vida. Nesse sentido, Monteschio, Gaíva e Moreira (2015), reforçam os achados e indicam que os motivos estão associados à cultura, estilo de vida e influência da sociedade, impactando diretamente na forma como a gestante ou parturiente compreende e assimila a prática do AM antes e após o parto. 
Tendo em vista que o desmame precoce é um problema mundial, a realização desse estudo se faz necessária, por buscar informações sobre os fatores que influenciam a interrupção do AME. Assim, ao analisar as produções científicas, espera-se contribuir para mudanças na prática profissional e também para o envolvimento e comprometimento dos gestores dos serviços de saúde em elaborarem estratégias com o objetivo de incentivar o AME. Por fim, pretende-se contribuir para a melhoria da qualidade da alimentação das crianças e também para a prevenção dos agravos decorrentes da ausência desse aleitamento. Sendo assim, o objetivo deste estudo é identificar na literatura científica disponível os fatores que influenciam na interrupção precoce do AME.

\section{Metodologia}

Neste estudo, optou-se pela abordagem metodológica da revisão integrativa da literatura, a qual segue as aproximações com a metodologia de síntese de conhecimento e a incorporação da aplicabilidade de resultados proposta por Souza, Silva e Carvalho (2010).

De acordo com Mendes, Silveira e Galvão (2008), na revisão integrativa da literatura é preciso percorrer seis etapas distintas, a saber: a primeira tratase da identificação do tema e seleção da hipótese ou questão de pesquisa para a elaboração da revisão integrativa; na segunda etapa são estabelecidos critérios para inclusão e exclusão de estudos/ amostragem ou busca na literatura; na terceira, são definidas as informações a serem extraídas dos estudos selecionados; na quarta etapa serão avaliados os estudos incluídos na revisão integrativa; na quinta serão discutidos os resultados; e na última serão apresentados os achados.

A pesquisa descrita nesse estudo ocorreu entre os meses de fevereiro e abril de 2020, iniciando-se as buscas de publicações, bem como as suas respectivas leituras. Para este estudo tem-se como questão central, a saber: quais são os fatores que determinam a interrupção precoce do aleitamento materno exclusivo? A pesquisa foi realizada no portal da Scientific Eletronic Library Online (SciELO) tendo como recorte temporal o período entre os anos de 2014 a 2019, a fim de discutir sobre as evidências científicas dos últimos 5 anos. Os descritores utilizados para busca foram: Aleitamento materno "and" Desmame precoce "and" Enfermagem, sendo realizado um cruzamento envolvendo os três descritores, resultando no total de 32 artigos.

Aos 32 artigos foram aplicados os critérios de inclusão e exclusão. Sendo que os critérios de inclusão adotados para a pesquisa foram: todos os artigos científicos que abordem o tema central da pesquisa; publicações disponíveis na base de dados do portal da SciELO; publicados entre os anos de 2014 e 2019; disponibilidade do material na íntegra online e gratuita; estar disponível na língua portuguesa. E definiram-se como critério de exclusão, estudos que se 
repetiam nas bases de dados e artigos que não respondiam à questão norteadora do trabalho. Em posse dos achados da pesquisa, os artigos foram analisados e discutidos com aproximações na Análise de Conteúdo de Bardin (2016). Sendo que para essa análise, os dados foram compilados e inseridos em um quadro sinóptico, contendo as informações de autor (es), título do artigo, periódico, ano, delineamento da pesquisa, procedência do estudo e nível de evidência.

Após a leitura dos achados e construção do quadro sinóptico, foram apresentados os resultados por meio de categorias temáticas, onde são discutidos os dados obtidos, possibilitando ao leitor a avaliação da aplicabilidade da revisão integrativa elaborada. Neste estudo observaram-se os aspectos éticos para pesquisa, respeitando os preceitos de autoria, bem como as citações de autores e/ou produções relacionadas à pesquisa, conforme a Norma Brasileira 6023:2018.

\section{Resultados e discussão}

Para a realização das buscas definiu-se como base de dados o portal da SciELO. Os descritores utilizados foram "Aleitamento materno", "Desmame precoce", "Enfermagem", considerando a aproximação dos mesmos com o tema em estudo. Durante a busca foi utilizado o operado booleano "AND", uma vez que o mesmo favorece a intersecção no decorrer da procura. A partir da utilização da estratégia de busca foram encontrados 32 materiais científicos, destes, 18 foram excluídos por estarem fora do período de estudo.

Inicialmente, os artigos foram selecionados pelo nome, de acordo com o resumo, e posteriormente, foram lidos apenas os que tinham compatibilidade com o tema. Dentre os 14 artigos selecionados através do resumo, após a leitura dos mesmos, foi utilizado para a pesquisa apenas nove que se referiram diretamente ao tema. Cabe salientar que todos os artigos foram lidos na íntegra, visando maior compreensão dos mesmos.

$\mathrm{Na}$ seção a seguir serão apresentadas as relações dos artigos selecionados. Os resultados são descritos no Quadro 1, sendo identificados por números ordinais romanos, indicando os seus autores, título, periódico em que o estudo foi publicado e o ano da publicação. No mesmo quadro é apresentado ainda o delineamento da pesquisa, que indica qual o tipo de estudo realizado, a procedência do estudo e por fim o nível de evidência.

Para identificação do nível de evidência dos artigos, foi utilizada a classificação proposta por Melnyk e Fineout-Overholt (2005): nível 1 evidências provenientes de revisão sistemática ou meta-análise de todos os relevantes ensaios clínicos randomizados controlados ou oriundos de diretrizes clínicas, baseadas em revisões sistemáticas de ensaios clínicos randomizados controlados; nível 2 - evidências derivadas de pelo menos um ensaio clínico randomizado controlado bem delineado; nível 3 - evidências obtidas de ensaios clínicos bem delineados sem randomização; nível 4 - evidências provenientes 
de estudo de coorte e de caso-controle bem delineados; nível 5 - evidências originárias de revisão sistemática de estudos descritivos e qualitativos; nível 6 - evidências derivadas de um único estudo descritivo ou qualitativo; nível 7 - evidências oriundas de opinião de autoridades e/ou relatórios de comitê de especialistas.

Quadro 01. Apresentação dos resultados da pesquisa bibliográfica.

\begin{tabular}{|c|c|c|c|c|c|c|c|}
\hline $\mathbf{N}^{0}$ & Autor(es) & Título do artigo & Periódico & Ano & $\begin{array}{c}\text { Delineamento } \\
\text { da pesquisa }\end{array}$ & $\begin{array}{l}\text { Procedência } \\
\text { do estudo }\end{array}$ & $\begin{array}{l}\text { Nível de } \\
\text { evidência }\end{array}$ \\
\hline I & Maciel et al. & $\begin{array}{c}\text { Aleitamento } \\
\text { materno em } \\
\text { crianças indígenas } \\
\text { de dois municípios } \\
\text { da Amazônia } \\
\text { Ocidental Brasileira }\end{array}$ & $\begin{array}{l}\text { Acta Paul. } \\
\text { Enferm. }\end{array}$ & 2016 & $\begin{array}{l}\text { Estudo } \\
\text { descritivo } \\
\text { do tipo } \\
\text { transversal }\end{array}$ & Acre, Brasil & Nível 6 \\
\hline II & $\begin{array}{l}\text { Prado, } \\
\text { Fabbro e } \\
\text { Ferreira }\end{array}$ & $\begin{array}{l}\text { Desmame precoce } \\
\text { na perspectiva } \\
\text { de puérperas: } \\
\text { uma abordagem } \\
\text { dialógica }\end{array}$ & $\begin{array}{l}\text { Rev. Texto } \\
\text { Contexto } \\
\text { Enferm. }\end{array}$ & 2016 & $\begin{array}{l}\text { Metodologia } \\
\text { comunicativa } \\
\text { crítica }\end{array}$ & $\begin{array}{l}\text { São Paulo, } \\
\text { Brasil }\end{array}$ & Nível 6 \\
\hline III & $\begin{array}{l}\text { Pinheiro } \\
\text { et al. }\end{array}$ & $\begin{array}{l}\text { Prevalência e } \\
\text { fatores associados } \\
\text { à prescrição/ } \\
\text { solicitação de } \\
\text { suplementação } \\
\text { alimentar em } \\
\text { recém-nascidos }\end{array}$ & $\begin{array}{l}\text { Rev. } \\
\text { Nutrição }\end{array}$ & 2016 & $\begin{array}{l}\text { Estudo } \\
\text { transversal }\end{array}$ & $\begin{array}{l}\text { Rio Grande } \\
\text { do Norte, } \\
\text { Brasil }\end{array}$ & Nível 6 \\
\hline IV & Santos et al. & $\begin{array}{c}\text { Aleitamento } \\
\text { materno e diarreia } \\
\text { aguda entre } \\
\text { crianças cadastradas } \\
\text { na Estratégia Saúde } \\
\text { da Família }\end{array}$ & $\begin{array}{l}\text { Rev. Texto } \\
\text { Contexto } \\
\text { Enferm. }\end{array}$ & 2016 & $\begin{array}{l}\text { Estudo } \\
\text { descritivo } \\
\text { do tipo } \\
\text { transversal }\end{array}$ & $\begin{array}{l}\text { Maranhão, } \\
\text { Brasil }\end{array}$ & Nível 6 \\
\hline $\mathrm{V}$ & $\begin{array}{l}\text { Mariano } \\
\text { et al. }\end{array}$ & $\begin{array}{c}\text { Aleitamento } \\
\text { materno exclusivo } \\
\text { e autoeficácia } \\
\text { materna entre } \\
\text { mulheres em } \\
\text { situação de } \\
\text { violência por } \\
\text { parceiro íntimo }\end{array}$ & $\begin{array}{l}\text { Rev. Texto } \\
\text { Contexto } \\
\text { Enferm. }\end{array}$ & 2016 & $\begin{array}{l}\text { Estudo } \\
\text { transversal }\end{array}$ & $\begin{array}{l}\text { Santa } \\
\text { Catarina, } \\
\text { Brasil }\end{array}$ & Nível 6 \\
\hline VI & $\begin{array}{c}\text { Monteschio, } \\
\text { Gaíva e } \\
\text { Moreira }\end{array}$ & $\begin{array}{c}\text { O enfermeiro } \\
\text { frente ao desmame } \\
\text { precoce na consulta } \\
\text { de enfermagem à } \\
\text { criança }\end{array}$ & $\begin{array}{l}\text { Rev. Bras. } \\
\text { Enferm. }\end{array}$ & 2015 & $\begin{array}{c}\text { Estudo } \\
\text { descritivo, com } \\
\text { abordagem } \\
\text { qualitativa }\end{array}$ & $\begin{array}{l}\text { Mato } \\
\text { Grosso, } \\
\text { Brasil }\end{array}$ & Nível 6 \\
\hline VII & $\begin{array}{l}\text { Campos } \\
\text { et al. }\end{array}$ & $\begin{array}{l}\text { Práticas exclusivas } \\
\text { de amamentação } \\
\text { relatadas pelas } \\
\text { mães e introdução } \\
\text { de líquidos } \\
\text { adicionais }\end{array}$ & $\begin{array}{c}\text { Rev. } \\
\text { Latino-Am. } \\
\text { Enfermagem }\end{array}$ & 2015 & $\begin{array}{l}\text { Estudo } \\
\text { descritivo } \\
\text { do tipo } \\
\text { transversal }\end{array}$ & $\begin{array}{l}\text { São Paulo, } \\
\text { Brasil }\end{array}$ & Nível 6 \\
\hline
\end{tabular}




\begin{tabular}{|c|c|c|c|c|c|c|c|}
\hline No & Autor(es) & Título do artigo & Periódico & Ano & $\begin{array}{c}\text { Delineamento } \\
\text { da pesquisa }\end{array}$ & $\begin{array}{c}\text { Procedência } \\
\text { do estudo }\end{array}$ & $\begin{array}{c}\text { Nível de } \\
\text { evidência }\end{array}$ \\
\hline VIII & $\begin{array}{c}\text { Oliveira } \\
\text { et al. }\end{array}$ & $\begin{array}{c}\text { Amamentação e as } \\
\text { intercorrências que } \\
\text { contribuem para o } \\
\text { desmame precoce }\end{array}$ & $\begin{array}{c}\text { Rev. Gaúcha } \\
\text { Enferm. } \\
\text { descritivo- } \\
\text { exploratório } \\
\text { com } \\
\text { abordagem } \\
\text { qualitativa }\end{array}$ & $\begin{array}{c}\text { Mato } \\
\text { Grosso, } \\
\text { Brasil }\end{array}$ & Nível 6 \\
\hline IX & $\begin{array}{c}\text { Rocci e } \\
\text { Fernandes }\end{array}$ & $\begin{array}{c}\text { Dificuldades } \\
\text { no aleitamento } \\
\text { materno e } \\
\text { influência no } \\
\text { desmame precoce }\end{array}$ & $\begin{array}{c}\text { Rev. Bras. } \\
\text { Enferm. }\end{array}$ & 2014 & $\begin{array}{c}\text { Estudo de } \\
\text { coorte }\end{array}$ & $\begin{array}{c}\text { São Paulo, } \\
\text { Brasil }\end{array}$ & Nível 4 \\
\hline
\end{tabular}

Fonte: Autores (2020).

Quanto aos anos de publicação, identificaram-se 11\% dos artigos publicados em 2014, 33\% em 2015 e 56\% em 2016. Quanto aos periódicos das publicações, identificaram-se 33\% dos artigos na Revista Texto e Contexto Enfermagem, 22\% na Revista Brasileira de Enfermagem e 11\% em cada uma das demais revistas: Revista de Nutrição, Revista Gaúcha de Enfermagem, Acta Paulista de Enfermagem e Revista Latino-Americana de Enfermagem.

Em relação ao nível de evidência, $89 \%$ dos artigos, apresentaram nível 6, que são os estudos descritivos (transversais). A prevalência de estudos transversais se dá pelo fato de eles serem relativamente baratos, simples e rápidos, pois não requerem seguimento. Além disso, são adequados para descrever as características de fatores de risco conhecidos em uma população, assim como, identificar novos fatores de risco, conforme indicam Fletcher, Fletcher e Fletcher (2014).

E 11\% apresentou nível 4, que são evidências provenientes de estudo de coorte. $\mathrm{O}$ termo coorte é utilizado para designar o acompanhamento em determinado período de tempo de grupos de pessoas que têm em comum um conjunto de características (SUZUMURA et al., 2008).

Os principais resultados desses artigos foram elencados em cinco categorias temáticas: Categoria I - Características maternas; Categoria II - Mitos e crenças sobre o aleitamento materno; Categoria III - Manejo na amamentação; Categoria IV - Substitutos do leite materno; Categoria V Orientação profissional quanto à lactação.

A primeira categoria é intitulada "Características maternas" sendo um espaço destinado para a identificação dos fatores de risco relacionados à mãe e que levam ao desmame precoce. A segunda categoria é intitulada "Mitos e crenças sobre o aleitamento materno" perfazendo sobre a influência dos aspectos culturais que condicionam a interrupção do AM. A terceira categoria denominada "Manejo na amamentação" discorre sobre os problemas relacionados com a lactação e a utilização de acessórios que comprometem a sua eficácia. A quarta categoria designada "Substitutos do leite materno" 
descreve como ocorre a alimentação complementar oferecido ao lactente precocemente e os impactos acarretados por esta prática. E, por fim, a quinta categoria denominada "Orientação profissional quanto à lactação" enunciando sobre como o profissional pode impactar na prática da amamentação.

\section{Características maternas}

Estão incluídos, nesta categoria, todos os fatores de risco relacionados à mãe que levaram ao desmame precoce. Referente a estas características foram associados os seguintes fatores: inserção no mercado de trabalho, mulheres em situação de violência, consulta no pré-natal, primiparidade e idade materna.

O trabalho materno foi citado em cinco artigos como um fator importante para o desmame precoce. Os achados demonstram que nas últimas décadas a participação da mulher no mercado de trabalho tem aumentado, implicando em uma mudança negativa no seu comportamento em relação à amamentação. Monteschio, Gaíva e Moreira (2015), complementam que o retorno ao trabalho provoca angústia e ansiedade às mulheres, levando muitas delas a prática inadequadas, como a introdução precoce de alimentos e o uso de mamadeiras.

Diante do exposto, Oliveira et al. (2015) perfazem que a insuficiência de informações no período pré-natal e a falta de empenho dos profissionais de saúde ao realizarem um planejamento de estratégias que visam proteger a continuidade do aleitamento, contribuem para o agravamento desta situação.

Outro fator importante e que predispõe o desmame precoce é discutido no estudo de Mariano et al. (2016). Os autores mencionados realizaram um estudo transversal, desenvolvido no Centro de Referência da Saúde da Mulher (CRSM), onde buscaram caracterizar a prática da amamentação entre vítimas de violência por parceiro íntimo. Os achados evidenciam que mulheres em situação de violência podem vir a desenvolver no puerpério situações como: depressão, ansiedade, estilo de vida prejudicial, além de baixa autoestima e autoeficácia, sendo que todos esses fatores estão relacionados com a ocorrência do desmame precoce.

O mesmo estudo identificou que quanto mais precocemente for iniciado o pré-natal e quanto maior o número de consultas realizadas, os níveis de autoeficácia na amamentação são mais elevados. Conforme Mariano et al. (2016) as mulheres em situação de violência tendem a buscar mais tardiamente o pré-natal e a realizar menor número de consultas do que as preconizadas pelo MS.

Outra causa de desmame precoce, referida nos artigos VII e IX, foi a baixa idade materno. Rocci e Fernandes (2014) apresentam uma pesquisa de coorte, com amostra de 225 mulheres entrevistadas no puerpério mediato e no $15^{\circ}, 30^{\circ}, 60^{\circ}, 120^{\circ}$ e $180^{\circ}$ dias após a alta. A média de idade das participantes que compuseram a amostra foi de 25,7 anos, sendo identificado que ao final do monitoramento de 180 dias, $34,1 \%$ de mães permaneciam aleitando 
exclusivamente. Esse achado corrobora com os resultados do estudo de Campos et al. (2015), onde sugerem que, em função da falta de experiência as mães jovens são mais facilmente influenciadas pelos familiares no que se refere a práticas prejudiciais ao AM.

Com relação à paridade, dois artigos consideraram como fator de risco para o desmame precoce a primiparidade. Nesse cenário, o estudo de Oliveira et al. (2015) identifica que a inexperiência associada ao déficit de informações quanto à amamentação, podem estar relacionados com a insegurança materna, resultando em maiores dificuldades para amamentar, representando um período de intenso aprendizado para o trinômio, no qual a mulher necessita de muito apoio e orientação.

Concernente com esses aspectos, Monteschio, Gaíva e Moreira (2015), corroboram que a atuação do enfermeiro é destacada, não apenas para auxiliar no manejo da amamentação, mas especialmente para promover autoconfiança da mãe e difundir orientações que ultrapassem o limite da aplicabilidade de técnicas pré-definidas.

\section{Mitos e crenças sobre o aleitamento materno}

Entre os fatores que influenciam no desmame precoce, nessa categoria temos o uso de chupeta, leite fraco, leite insuficiente e que não sustenta, provoca cólicas no lactente, choro do bebê interpretado como fome e inferências familiares.

O leite fraco ou insuficiente foi citado em seis artigos e que provoca cólicas no bebê em dois estudos. De acordo com Rocci e Fernandes (2014), a cultura e a inferência de familiares interferem fortemente nas crenças maternas no que tange ao leite fraco, podendo levar as mães a acreditarem que não são capazes de produzir a quantidade suficiente de alimento.

Prado, Fabbro e Ferreira (2016) apresentam uma pesquisa em que utilizam a metodologia comunicativa crítica como delineamento, realizada no interior do estado de São Paulo, tendo como participantes 12 mães que praticaram o desmame precoce. $\mathrm{O}$ estudo permitiu descrever o processo do AM a partir da visão e vivência destas mulheres, sendo identificados alguns mitos relacionados ao aleitamento materno, entre eles, a queixa que o leite é fraco, constatado em $47 \%$ das falas.

A mesma temática é abordada no artigo VI, onde os autores Monteschio, Gaíva e Moreira (2015) descrevem que as mães participantes do estudo, referiram que seu leite é fraco e que não sustenta e acreditam na qualidade do leite artificial, pois associam o sono da criança com satisfação alimentar. Sob esse limiar, o estudo VII de Campos et al. (2015), elenca que a água foi o líquido mais frequente administrado pelas mães, sendo como motivo a crença de que elas devem oferecê-lo às crianças para saciar sua sede, satisfazendo sua necessidade e assim, minimizando o choro. 
Cabe citar aqui sobre um fator que, segundo Campos et al. (2015), também predispõe o desmame precoce: desconhecimento das mães sobre o processo de AM. De acordo com seu estudo, foi possível descobrir que a maioria das nutrizes entrevistadas acreditava que dar líquidos e frutas antes dos seis meses de idade é apropriado, independente da amamentação.

Em relação à chupeta, este acessório tem sido frequentemente associado ao desmame precoce, pois se percebem manifestações de dificuldades das mães em lidar com o choro do bebê (ALVARENGA et al.; 2017). Dos artigos estudados, quatro mostram que o uso da chupeta tem influência na duração do AM. No estudo realizado por Santos et al. (2016), constatou-se que o uso de chupeta implica na redução do número de mamadas por dia e, como consequência, há menor estimulação mamilo-areolar e menor produção de leite, levando a necessidade de suplementação.

Em alusão ao exposto, no artigo I, os autores Maciel et al. (2016) apresentam um estudo descritivo do tipo transversal, realizado no estado do Acre, tendo como participantes 91 mulheres e 94 crianças, todas indígenas pertencentes as etnias Nukini, Nawa e Poyanawa. Os resultados demonstram que o uso da chupeta e sucção do dedo foi citado por menos de $10 \%$ das mães, mostrando que tais práticas não são prevalentes entre os indígenas das etnias estudadas.

Em contrapartida com as afirmações supracitadas, os autores Oliveira et al. (2015), sugerem que a chupeta pode representar um fator dificultador na prática do AM e não a causa direta da interrupção da amamentação. Os mesmos autores acrescentam que, o mais importante não seja a retirada da chupeta, mas a tentativa de compreender e solucionar os problemas que motivaram o seu uso.

Pesquisa realizada em um hospital municipal, localizado na zona leste de São Paulo, conduzida por Rocci e Fernandes (2014), aponta que apenas 30\% das mulheres estudadas haviam recebido orientações sobre o uso de chupetas. Este fato mostra a falha no acompanhamento das mães pelos profissionais durante o pós-parto, assim como no pré-natal, períodos que são fundamentais para a orientação dessas mulheres sobre as práticas que podem comprometer o AME.

Campos et al. (2015), afirmam que o comportamento não é apenas influenciado pelo conhecimento intelectual, mas também pelas crenças e culturas presentes no ambiente real das mulheres. Desta forma, o conhecimento nem sempre garante que a amamentação seja realizada de forma adequada. No âmbito familiar, a nutriz executa um processo consciente ou inconsciente de escolher um membro da família como referência de apoio, sendo geralmente uma pessoa mais velha, experiente e que tenha vivenciado a maternidade, como a mãe e a avó. 
No estudo realizado por Oliveira et al. (2015), foi apontado que a figura da avó materna se configura como fator negativo para a manutenção do AM, principalmente o exclusivo. Os mesmos autores salientam que as práticas de apoio das avós são influenciadas por suas próprias experiências e pelo contexto sociocultural que estão inseridas.

Diante do exposto, o artigo VI destaca a importância do enfermeiro na construção de valores sobre o $\mathrm{AM}$, junto à nutriz e sua família, valorizando $\mathrm{a}$ sua rede de apoio e incluindo-a nos programas de educação em saúde sobre o AM. E concluem que é necessário respeitar as crenças e sentimentos, assim os profissionais estarão mais preparados para apoiar e contribuir para o sucesso da amamentação.

\section{Manejo na amamentação}

Outro fator que influencia na amamentação são os traumas mamilares/ dor, mamilos planos ou invertidos e a pega correta. Os problemas mamários foram citados em quatro artigos. Neste contexto, Monteschio, Gaíva e Moreira (2015) destacam que as lesões nos mamilos são provocadas, especialmente, pela técnica incorreta da amamentação, além disso, estas alterações podem comprometer a qualidade do AM.

Em seu estudo, Rocci e Fernandes (2014) identificaram que 70,5\% das mulheres entrevistadas referiram a pega como maior obstáculo no manejo da amamentação. Ainda foi possível observar com tal pesquisa que as nutrizes que citaram dificuldade em amamentar já na pré-alta, apresentaram no $60^{\circ}$ dia um percentual de desmame significativamente maior que aquelas que não tiveram dificuldades (10,9\% v.s 3,3\%).

Ao encontro disso, o estudo II de Prado, Frabbro e Ferreira (2016) constatou que a necessidade da presença do bico para amamentar foi um elemento marcante relatado pelas mulheres entrevistadas, sendo relacionado com a pega correta do mamilo e, assim, o sucesso na prática do AM. Além disso, os mesmos autores trazem que as mães tentaram diversas formas para reverter a não protusão do bico, utilizando para isso algumas estratégias não recomendadas pelo MS.

Conforme Monteschio, Gaíva e Moreira (2015), os sentimentos de dor, desconforto, estresse e insegurança materna provocada pelos problemas mamários durante o AME levam as lactantes a introduzir a mamadeira, com a finalidade de aliviar os sintomas e suprir as necessidades nutricionais da criança. Concernente ao exposto, Santos et al. (2016), em seu estudo realizado no estado do Maranhão, com crianças menores de 12 meses de idade cadastradas em uma Estratégia Saúde da Família (ESF), mostrou que lactentes que usaram a mamadeira tinham 16 vezes mais chances de não receberem AM. Desta forma, o uso de mamadeira influenciou negativamente na prática de 
amamentação, mostrando que quanto menos utilizado este acessório, houve mais probabilidade de ocorrer o AM e vice-versa.

De acordo com Monteschio, Gaíva e Moreira (2015), o uso da mamadeira prejudica a criança integralmente em seus aspectos biopsicossociais, comprometem o seu crescimento e desenvolvimento. Além destes problemas, os mesmos autores afirmam que quando a mamadeira é introduzida de maneira precoce, acredita-se que ela possa gerar "confusão de bicos", devido às diferenças existentes entre a sucção na mama e no bico artificial.

Uma prática muito difundida e mencionada no artigo III dos autores Pinheiro et al. (2016) é o uso do copo para alimentação. Conforme os escritores, este método é excelente para alimentar o recém-nascido, especialmente os prematuros, para que desenvolvam a habilidade de sucção, sem prejuízo da sucção do seio materno. Os mesmos concluem que, é um dever dos profissionais da saúde, principalmente o enfermeiro, desencorajar o uso de mamadeiras, com o propósito de melhorar a qualidade de vida das crianças e contribuir para a redução de mortalidade infantil pela manutenção do AM.

\section{Substitutos do leite materno (alimentação complementar prematura)}

Os principais fatores associados ao desmame precoce nessa temática, foram a introdução de outros tipos de leite, líquidos não nutritivos (água e chás) e outros alimentos.

Entende-se como alimentação complementar prematura a adição de alimentos líquidos ou sólidos, diferentes do leite materno, oferecidos ao lactente com menos de seis meses de idade. A introdução precoce dos alimentos pode ser nociva à saúde da criança (RODRIGUES;GOMES, 2014). De acordo com Campos et al. (2015) alguns riscos associados à introdução precoce de líquidos às dietas das crianças incluem: maior número de episódios de diarreia, maior número de hospitalizações por doença respiratória, exposição do bebê à contaminação de alimentos, aumento no risco de mortalidade na infância e desenvolvimento inadequado da musculatura facial e dentição.

No estudo de Santos et al. (2016) os autores observaram que as crianças que receberam $\mathrm{AME}$ apresentaram menor chance de diarreia aguda e aquelas que usaram mamadeira, água e mingau possuíam 2,6 vezes mais chances de apresentarem esta patologia. A complementação do leite materno com líquidos não nutritivos como água e chás é desnecessária, no entanto, neste mesmo estudo, os autores revelam que essa é uma prática difundida culturalmente, pois as mães acreditam que os líquidos são necessários para a criança devido à sede e assim adotam esta prática, principalmente quando há o aumento da temperatura ambiente, para mantê-los hidratados.

Os autores Pinheiro et al. (2016) realizaram um estudo transversal em um alojamento conjunto de um hospital "Amigo da criança", em uma cidade no estado do Rio Grande do Norte. Foram incluídas na pesquisa as puérperas 
e recém-nascidos internados no setor, totalizando uma amostra de 113 díades mãe e filho. $\mathrm{O}$ estudo identificou que a hipogalactia (diminuição da secreção láctea) foi o motivo mais frequente para indicação de suplemento alimentar.

Ao realizar uma análise bivariada com os fatores associados entre a hipogalactia e as características maternas e do $\mathrm{RN}$, os autores associaram o parto cesáreo como um fator desencadeante, sendo a via de parto prevalente nas mulheres que compuseram a amostra do estudo, totalizando $61,1 \%$. Além disso, também foram constatados que a dor decorrente do pós-operatório e o tempo decorrido para o início da amamentação são fatores que contribuem para o retardo da amamentação nas primeiras horas de vida.

Outro dado evidenciado pelos mesmos autores refere-se à quantidade e frequência de prescrição/solicitação de leite artificial ofertado nas primeiras seis horas de vida dos recém-nascidos e sem qualquer indicação. Em sua maioria o volume prescrito era de $30 \mathrm{ml}$ por etapa e até oito vezes ao dia, o que demonstra uma fragilidade na avaliação dos recém-nascidos pelos profissionais, sendo desconsideradas as reservas energéticas e o tempo natural da apojadura.

Além dos riscos relacionados à saúde da criança e da lactante, bem como as alterações no vínculo do binômio mãe-bebê, o uso do leite artificial traz repercussões nos orçamentos familiar e do estado. Esse tema foi evidenciado no artigo II, onde os autores Prado, Fabbro e Ferreira (2016) identificaram através das falas das participantes que, com o desmame houve maior gasto financeiro da família, devido à compra de mamadeiras e leites artificiais.

\section{Orientação profissional quanto à lactação}

Verificou-se que ao mesmo tempo em que os profissionais de saúde podem influenciar positivamente as mulheres que amamentam, podem também ser uma fonte de suporte negativo quando proporcionam informações inconsistentes e práticas negativas a este estrato populacional.

O profissional da saúde foi citado em apenas dois artigos como um fator de favorecimento para o desmame precoce. Rocci e Fernandes (2014) citam o pediatra como sujeito que deveria ser o defensor do AME, porém, em seu estudo identificaram que o abandono desta prática, conforme referência das mães entrevistadas foi influenciada em $11,7 \%$ das vezes por esse profissional, que indicou a complementação do leite materno com fórmulas industrializadas.

Em consonância com o exposto, no artigo III os autores Pinheiro et al. (2016) verificaram em seu estudo, que a enfermagem foi a responsável pelo maior número de solicitações de leite artificial, quando comparada às prescrições do médico pediatra. No mesmo estudo, também foi possível observar que o turno do dia teve maior frequência da utilização de suplemento.

Em contrapartida, os resultados evidenciados por Monteschio, Gaíva e Moreira (2015) mostraram que, na maioria das vezes, os enfermeiros utilizaram estratégias apropriadas para o manejo dos problemas mais comuns na 
amamentação, transparecendo comprometimento e responsabilidade com as recomendações e preceitos do MS sobre o AM.

Nesse sentido, Santos et al. (2016) apontam que os profissionais da saúde têm muitos desafios e precisam avançar para a apropriação de tecnologias voltadas para fortalecer as práticas educativas e a promoção ao AM. Sob esse limiar, Oliveira et al. (2015) reforçam que estes profissionais necessitam serem bem treinados para agirem de forma humanizada e individualizada, fazendo com que o cuidado não se torne apenas a aplicação de técnicas, mas sim uma prática complexa e que considera as particularidades de cada mulher.

\section{Considerações Finais}

Os resultados e discussões desse estudo possibilitaram detectar que, apesar dos inúmeros fatores que influenciam o desmame precoce, a maioria deles é suscetível de retificação. A síntese dos diferentes estudos evidenciou que a amamentação é um processo que ultrapassa o simples desejo e decisão autônoma das mulheres, pois exibe forte determinação sociocultural e histórica.

Dentre todos os fatores que influenciam no desmame precoce, o trabalho da mulher foi o fator mais citado entre os autores. A inserção da mulher no mercado de trabalho se oportuniza como uma necessidade social, entretanto, a capacidade de continuar amamentando no regresso do trabalho é multifatorial, já que as mulheres tentam equilibrar as demandas familiares e laborais com a disponibilidade de cuidados com o lactente.

Junto com esse fator, outra questão que é destacada e que se pode interligar com as afirmações supracitadas é o uso de mamadeiras e substitutos do leite, pois a lactante que trabalha fora acaba utilizando-se da mamadeira precocemente, devido o fim do período de licença maternidade. E a mulher que não conhece seus direitos como nutriz, não goza dos benefícios previstos em lei, como os horários concedidos para amamentação durante a jornada de trabalho.

Fica evidente que ainda existem lacunas entre o conhecimento e a incorporação do saber sobre AM com gestantes e nutrizes. Nesse cenário, é conveniente ressaltar a importância da equipe de saúde, em especial, a participação do enfermeiro, na tentativa de minimizar o problema do desmame precoce. A equipe deve atuar junto a essas mulheres desde o pré-natal para sensibilizar e informar acerca do valor da amamentação exclusiva até o sexto mês de idade.

E por fim, os resultados incitaram sobre a importância de conhecer os fatores de risco que levam às mães a cessarem o AME, sendo possível visibilizar estratégias e intervenções que possam auxiliar na prática assistencial dos profissionais de saúde. Nesse sentido, espera-se que os resultados aqui apresentados possibilitem a ampliação do conhecimento e permita uma reflexão acerca das ações de promoção e apoio a amamentação. 
Sendo assim, esse estudo possibilitou compreender quais fatores influenciam na interrupção do AME, sendo possível identificar os obstáculos relacionados à prática da amamentação. Esses resultados responderam ao objetivo da pesquisa e oferecem o estimulo necessário para a realização de estudos futuros que abarquem a temática do desmame precoce, com vistas à qualificação do ensino e da formação profissional.

\section{Referências}

ASSOCIAÇÃO BRASILEIRA DE NORMAS TÉCNICAS. NBR 6023: informação e documentação - referências - elaboração. Rio de Janeiro. 2018.

ALVARENGA, S. C. et al. Fatores que influenciam o desmame precoce. Rev. Aquichán, Colômbia, v.17, n. 1, 2017.

ARAÚJO, M. F. et al. Avanços na norma brasileira de comercialização de alimentos para idade infantil. Revista de Saúde Pública, v. 40, n. 3, p. 513-520, 2006.

BARDIN, L. Análise de Conteúdo. Tradução: Luís Augusto Pinheiro. São Paulo: Edições 70, 2016.

BRASIL. Ministério da Saúde. Secretaria de Atenção à Saúde. Departamento de Atenção Básica. Saúde da criança: aleitamento materno e alimentação complementar. Ministério da Saúde, Secretaria de Atenção à Saúde, Departamento de Atenção Básica. $2^{a}$ ed. Brasília, 2015.

BRASIL. Ministério da Saúde. Secretaria de Atenção à Saúde. Departamento de Ações Programáticas Estratégicas. Bases para a discussão da Política Nacional de Promoção, Proteção e Apoio ao Aleitamento Materno. Ministério da Saúde, Secretaria de Atenção à Saúde, Departamento de Ações Programáticas Estratégicas. Brasília, 2017.

CAMPOS, A. M. S. et al. Práticas exclusivas de amamentação relatadas pelas mães e introdução de líquidos adicionais. Rev. Latino-Am. Enfermagem, Ribeirão Preto, v. 23, n. 2, p. 283-290, 2015.

FLETCHER, R. H.; FLETCHER, S. W.; FLETCHER, G. S. Epidemiologia clínica. $5^{a}$ ed. Porto Alegre: Artmed; 2014.

FUNDO DAS NAÇÕES UNIDAS PARA A INFÂNCIA. Apenas $\mathbf{4 0} \%$ das crianças no mundo recebem amamentação exclusiva no início da vida. Disponível em: $<$ https:/ / nacoesunidas.org/unicef-apenas-40-das-criancas-no-mundo-recebem-amamentacaoexclusiva-no-inicio-da-vida> Acesso em: 08 de maio de 2020.

INSTITUTO BRASILEIRO DE GEOGRAFIA E ESTATÍSTICA. Tábua completa de mortalidade para o Brasil - 2018: Breve análise da evolução da mortalidade no Brasil. Rio de Janeiro: IBGE, 2019. 
MACIEL, V. B. S. et al. Aleitamento materno em crianças indígenas de dois municípios da Amazônia Ocidental Brasileira. Acta Paul. Enferm., São Paulo, v. 29, n. 4, p. 469475, 2016.

MARIANO, L. M. B. et al. Aleitamento Materno Exclusivo e autoeficácia materna entre mulheres em situação de violência por parceiro íntimo. Texto contexto Enferm., Florianópolis, v. 25, n. 4, 2016.

MENDES, K. D. S.; SILVEIRA, R. C. C. P.; GALVAO, C. M. Revisão integrativa: método de pesquisa para a incorporação de evidências na saúde e na enfermagem. Texto Contexto - Enferm., Florianópolis, v. 17, n. 4, p. 758-764, 2008.

MONTESCHIO, C. A. C.; GAIVA, M. A. M.; MOREIRA, M. D. S. O enfermeiro frente ao desmame precoce na consulta de enfermagem à criança. Rev. Bras. Enferm., Brasília, v. 68, n. 5, p. 869-875, 2015.

NUNES, L. M. Importância do aleitamento materno na atualidade. Boletim Científico de Pediatria, v. 4, n. 3, p. 55-58, 2015.

OLIVEIRA, C. S. et al. Amamentação e as intercorrências que contribuem para o desmame precoce. Rev. Gaúcha Enferm., Porto Alegre, v. 36, n. spe, p. 16-23, 2015.

PINHEIRO, J. M. F. et al. Prevalência e fatores associados à prescrição/solicitação de suplementação alimentar em recém-nascidos. Rev. Nutr., Campinas, v. 29, n. 3, p. 367375, 2016.

PRADO, C. V. C.; FABBRO, M. R. C.; FERREIRA, G. I. Desmame precoce na perspectiva de puérperas: uma abordagem dialógica. Texto Contexto - Enferm., Florianópolis, v. 25, n. 2, 2016.

ROCCI, E.; FERNANDES, R. A. Q. Dificuldades no aleitamento materno e influência no desmame precoce. Rev. Bras. Enferm., Brasília, v. 67, n. 1, p. 22-27, 2014.

RODRIGUES, N. A.; GOMES, A. C. G. Aleitamento materno: fatores determinantes do desmame precoce. Enfermagem Revista, v. 17, n. 1, 2014.

SANTOS, F. S. et al. Amamentação e diarréia aguda entre crianças inscritas na Estratégia de Saúde da Família. Texto Contexto - Enferm., Florianópolis, v. 25, n. 1, 2016.

SOUZA, M. T.; SILVA, M. D.; CARVALHO, R. Revisão integrativa: o que é e como fazer. Einstein. v. 8, (1 Pt 1), 2010.

SUZUMURA, E. A. et al. Como avaliar criticamente estudos de coorte em terapia intensiva? Rev. Bras. Ter. Intensiva, São Paulo, v. 20, n. 1, p. 93-98, 2008.

WORLD HEALTH ORGANIZATION. The State of Food Security and Nutrition in the World. Washington, DC: WHO, 2019. 